\title{
RESEARCH
}

Open Access

\section{Cell therapy in patients with COVID-19 using Wharton's jelly mesenchymal stem cells: a phase 1 clinical trial}

Mahshid Saleh ${ }^{1}$, Amir Abbas Vaezi ${ }^{2}$, Rasoul Aliannejad ${ }^{3,4}$, Amir Ali Sohrabpour ${ }^{5}$, Seyedeh Zahra Fotook Kiaei ${ }^{6}$, Mahdi Shadnoush ${ }^{7}$, Vahid Siavashi ${ }^{8}$, Leila Aghaghazvini ${ }^{9}$, Batoul Khoundabi ${ }^{10}$, Shahriyar Abdoli ${ }^{11}$, Bahram Chahardouli ${ }^{12}$, Iman Seyhoun ${ }^{1 *+}$, Neda Alijani ${ }^{13^{*+}}$ (D) and Javad Verdi ${ }^{1{ }^{*+}}$

\section{Abstract}

Background: Mesenchymal stem cells (MSCs) have received particular attention because of their ability to modulate the immune system and inhibit inflammation caused by cytokine storms due to SARS-CoV-2. New alternative therapies may reduce mortality rates in patients with COVID19. This study aimed to assess the safety and efficacy of injecting intravenous Wharton's jelly-derived MSCs in patients with COVID-19 as a treatment.

Methods: In this study, five patients with severe COVID-19 were treated with Wharton's jelly-derived mesenchymal stem cells $(150 \times 106$ cells per injection). These patients were subject to three intravenous injections 3 days apart, and monitoring was done on days $0,3,6$, and 14 in routine tests, inflammatory cytokines, and flow cytometry of CD4 and CD8 markers. A lung CT scan was performed on base and days 14 and 28. In addition, IgM and IgG antibodies against SARS-CoV-2 were measured before and after treatment.

Results: The results showed that IL-10 and SDF-1 increased after cell therapy, but VEGF, TGF- $\beta$, IFN- $\gamma$, IL-6, and TNFa decreased. Routine hematology tests, myocardial enzyme tests, biochemical tests, and inflammation tests were performed for all patients before and after cell therapy on base and days 3, 6, and 14, which indicated the improvement of test results over time. COVID-19 antibody tests rose in 14 days after WJ-MSC injection. The total score of zonal involvement in both lungs was improved.

Conclusions: In patients, the trend of tests was generally improving, and we experienced a reduction in inflammation. No serious complications were observed in patients except the headache in one of them, which was resolved without medication. In this study, we found that patients with severe COVID-19 in the inflammatory phase respond better to cell therapy. More extensive clinical trials should be performed in this regard.

Trial registration: IRCT, IRCT20190717044241N2. Registered April 22, 2020.

Keywords: COVID-19, WJ-MSC, Cell therapy

\footnotetext{
*Correspondence: i.seihoon@gmail.com; n-alijani@sina.tums.ac.ir; JavadVerdi2019@gmail.com

${ }^{+}$Iman Seyhoun, Neda Alijani and Javad Verdi contributed equally to this work.

'Department of Applied Cell Sciences, School of Advanced Technologies in Medicine, Tehran University of Medical Sciences, Tehran, Iran

${ }^{13}$ Department of Infectious Diseases, Shariati Hospital, Tehran University of Medical Sciences, Tehran, Iran

Full list of author information is available at the end of the article
}

(C) The Author(s). 2021 Open Access This article is licensed under a Creative Commons Attribution 4.0 International License, which permits use, sharing, adaptation, distribution and reproduction in any medium or format, as long as you give appropriate credit to the original author(s) and the source, provide a link to the Creative Commons licence, and indicate if changes were made. The images or other third party material in this article are included in the article's Creative Commons licence, unless indicated otherwise in a credit line to the material. If material is not included in the article's Creative Commons licence and your intended use is not permitted by statutory regulation or exceeds the permitted use, you will need to obtain permission directly from the copyright holder. To view a copy of this licence, visit http://creativecommons.org/licenses/by/4.0/ The Creative Commons Public Domain Dedication waiver (http://creativecommons.org/publicdomain/zero/1.0/) applies to the data made available in this article, unless otherwise stated in a credit line to the data. 


\section{Introduction}

Coronavirus disease 2019 (COVID-19) has spread worldwide and was first detected in Wuhan, China, in December 2019 [1]. The virus has been widely distributed in different geographical areas [2]. SARS-CoV-2 primarily involves the respiratory system in addition to affecting other organs. Symptoms associated with lower respiratory tract infections, including fever, dry cough, and shortness of breath, have been reported in early case series isolated from Wuhan, China [3] Signs such as headache, dizziness, general weakness, vomiting, and diarrhea were also observed [4]. According to 2020 guidelines of the WHO, severe coronavirus disease is defined as follows: an adolescent or adult with clinical signs of pneumonia (fever, cough, shortness of breath, rapid breathing) plus one of the following signs: respiratory rate $>30$ breaths per minute; severe respiratory distress; or $\mathrm{SpO} 2<90 \%$ in ambient air [5].

At present, there is no specific drug to treat COVID19. The pathogenesis of HcoV19 is mediated through the detection of the ACE2 receptor by the spike protein of this virus [6-8]. Unfortunately, the ACE2 receptor is abundantly present in human cells, especially alveolar type II (ATII) and capillary endothelium. Immune cells such as B and T lymphocytes as well as macrophages in the bone marrow, lymph nodes, thymus, and spleen are negative for ACE2 [9].

Up to now, adjuvant therapeutic strategies such as corticosteroid-mediated reduction of inflammation, treatment of congestion using plasma, administration of antibiotics to treat secondary bacterial infections, nonspecific antiviruses, and so forth have not been effective in severe cases of COVID-19. The main reason for these treatments' failure is the cytokine storm created in the lungs by the virus $[10,11]$. SARS-CoV-2 can provoke severe cytokine storms in the lungs, including IL-2, IL-6, IL-7, GCSF, IP10, MCP1, MIP1A, and TNF $\alpha$, followed by edema, defective respiration, acute respiratory distress syndrome, acute heart damage, secondary infection [12], and eventually death [13]. More than 44 clinical trials on cell therapy in patients with COVID-19 have been registered at www.clinicaltrials.gov, www.chictr.org, and www.irct.ir and are being conducted. At present, different cells are used worldwide, including NK cells, T cells, and MSC cells of allogeneic and autologous origin from various tissues such as adipose, placenta, umbilical cord, Wharton's jelly, dental pulp, and menstrual blood [14]. The safety and efficacy of mesenchymal stem cells in reducing inflammatory lung disease have been indicated in animal models [15]. In human clinical trials, all reports indicated that stem cell injections were safe. Although the effects of cell therapy are not uniform, positive effects of cell therapy have been expressed in some cases but not in others [16]. In general, phase I and II clinical trials provide early immune results in patients with bronchopulmonary dysplasia (BPD), asthma, chronic obstructive pulmonary disease (COPD) [17], idiopathic pulmonary fibrosis (IPF) [18-21], and in patients with acute lung injury (ALI) [22].

Mesenchymal stem cells have strong immunomodulatory capabilities and may help treat and attenuate cytokines. MSCs have been implicated in several clinical trials in GVHD and SLE [23]. Many clinical trials in different conditions associated with these cells are currently performed for the disease [24]. MSCs have two main effects, namely immunomodulation [25] and differentiation [26]. Meanwhile, Wharton's jelly-derived MSCs are easily and noninvasively isolated from neonatal tissues [27] and show a higher pluripotential property compared to other sources of MSCs [28, 29]. Various studies have revealed that WJMSCs affect almost all immune cells and suppress CD3, CD8, and CD4 T cells [30]. These cells play a vital role in modulating the immune system by secreting large amounts of cytokines like IL-10, TGF-b, IL-6, and VEGF [31]. In a study by Zhang et al., $1 \times 106$ of WJ-MSC cells were injected in one dose for a critically severe-type patient. The patient underwent various treatments, such as antiviral therapies, plasma exchange, corticosteroids, and so on. Unfortunately, the patient's condition exacerbated after a few days, during which the treatment team used WJ-MSC cells for the patient. This study found that WJ-MSC cells could be an ideal and practical option for treating COVID19 patients [32]. The immunomodulatory effects of MSCs are triggered via activation of TLR receptor on MSC, which is stimulated by pathogen-related molecules such as LPS or double-stranded RNA of viruses [33, 34] like HCOVID19 [13]. MSCs secrete paracrine factors, including keratinocyte growth factor (KGF), angiopoietin-1 (Ang-1), prostaglandin E2 (PGE2), interleukin 10 (IL-10), and other tropic cytokines. These paracrine factors can increase alveolar fluid clearance, regulate epithelial and endothelial permeability of the lung, facilitate endothelial repair, and reduce inflammation [35]. MSCs can also release significant quantities of extracellular vesicles (EVs) that encapsulate cytokines, growth factors, signaling lipids, mRNAs, and functional microRNAs [36]. EVs are involved in cell-to-cell communication, cellular signal transduction, and metabolism, as well as local and long-distance immune modulation [37]. In this study, due to the low immunogenicity, easy accessibility, and unique capacity of WJ-MSCs to modulate the immune system to prevent cytokine storm and inflammation caused by SARS-CoV-2, the therapeutic potential of Wharton's jelly mesenchymal stem cells was used for patients with COVOD-19.

\section{Materials and methods}

\section{Patients and study design}

This pilot study was performed in Shariati Hospital of Tehran and was approved by the Ethics Committee of 
Tehran University of Medical Sciences (Code: IR.TUMS.VCR.REC.1399.203). This research was an open-label, single-center investigation. Patients with severe COVID-19 (according to WHO definition) were selected [38].

In this study, five patients with COVID-19 underwent cell therapy with Wharton's jelly-derived mesenchymal stem cells. Written consent was obtained from the patients before injection. Diagnosis and management of COVID-19 patients were performed based on the WHO guidelines [5] and Iran's diagnostic and treatment protocols. Patients were enrolled from July 21, 2020, to August 21, 2020, with the following.

\section{Inclusion criteria}

Inclusion criteria include the following: patients over 18 and under 65 years of age; clinical symptoms including positive COVID-19 confirmed by RT-PCR; SO2 < 93\% at rest or persistent hypoxia; laboratory tests CRP $<100$, d-dimer $<1000$, CPK twice normal levels, $\mathrm{LDH}<245$, Ferritin $<500$, increasing Troponin boost and lymphopenia $>1100$; respiratory failure requiring respiratory mask and involvement of over $50 \%$ of lungs with multilobar infiltrates.

\section{Exclusion criteria}

Exclusion criteria include the following: shift to other treatment modalities (according to the treating physician), septic shock, renal tissue insufficiency, presence of concomitant liver disorders such as increased liver enzymes or liver failure, presence of acute cardiovascular events during treatment, MI, DVT, and pulmonary embolism, enrollment in another study, and discontinuation of treatment.

\section{Isolation of HWJ-MSCS}

HWJ-MSC was produced by CellThecPharmed Company (Tehran, Iran) with GMP facilities approved by the food and drug administration of Iran. In brief, the umbilical cord (UC) was collected with an approximate length of $10 \mathrm{~cm}$. Wharton's jelly was isolated using a scalpel by scratching from vessels, and inner sub-amnion epithelium and the vessels were then removed. The collected WJ was placed in a separate petri dish. After the separation of Wharton's jelly, tissue fragments were cultured in a $75-\mathrm{cm}^{2}$ flask and digested by enzyme cocktails, and then a MSC cell culture medium was added to them. The flasks were incubated at $37^{\circ} \mathrm{C}$ for $2-3$ days without shaking, and the tissue fragments were allowed to adhere. Non-adherent cells were washed away, but adherent ones proliferated. In the next step, $80 \%$ confluency was reached after 7-10 days of growth, and the cells were transferred to another flask. Finally, cultured cells $\left(150 \times 10^{6}\right.$ cells $)$ up to passage five were used for each injection by transfer bags in GMP conditions together with heparin and human albumin serum. Confirmatory tests, including flow cytometry (CD73, CD34, CD90) and multiple lineage differentiation of MSCs (into fat, bone, and cartilage), were conducted according to the international society of cell therapy (ISCT). $150 \times$ $10^{6}$ cells were considered for each patient, injected intravenously (cephalic and basilic veins) three times a week for 3 days, namely days 0 , 3, and 6 for 15-20 min. Before injection, $100 \mathrm{mg}$ of hydrocortisone was injected into patients to prevent complications such as allergies. Patients were then monitored on days $0,3,6$, and 14 for routine tests, inflammatory cytokines, and flow cytometry for CD4 and CD8 markers.

All the patients were assessed for adverse events through clinical examinations, measurement of vital signs, and routine tests. Moreover, on days 0, 3, and 6, vital signs (heart rate, respiration, blood pressure, body temperature, oxygen saturation) were recorded during the injection and $1 \mathrm{~h}$ after it. Routine hematology parameters, myocardial enzymes, biochemistry, and inflammatory tests were performed before and after cell therapy.

SDF-1, IL-10, VEGF, TGF- $\beta$, IFN- $\gamma$, IL-6, and TNF $\alpha$ levels were measured in serum samples on days $0,3,6$, and 14. (ELISA R\&D, USA). COVID-19 IgM and IgG antibodies were measured the day before treatment and 14 days after it (Ideal Tashkhis Atieh, Iran).

\section{Flow cytometry procedure}

Peripheral blood CD4 and CD8 markers were assessed by flow cytometry. Briefly, $100 \mu \mathrm{l}$ of whole blood was poured into three separate test tubes, each containing $10 \mu \mathrm{l}$ of Anti-Hu CD4 PE (Exbio, Czech Republic), CD8 FITC (Exbio, Czech Republic), and Anti-Hu antibodies. CD45 PerCP (Cytognos, Spain) was mixed well and incubated at room temperature for $30 \mathrm{~min}$. The red blood cells were lysed using RBC lysis buffer solution (APRAD, Iran) for $5 \mathrm{~min}$ at $300 \mathrm{~g}$. The supernatant was then discarded, and the cells were suspended with $0.3-0.5 \mathrm{ml}$ PBS. The samples were immediately read using flow cytometry (Sysmex Partec Pas III, Germany).

\section{Statistical analysis}

Some frequency tables and graphs were used to describe the individual data. The data were analyzed using the statistical package IBM SPSS version 26.0 (Statistical Package for the Social Sciences, Chicago, IL). The categorical variables are expressed as proportions and frequencies. Kolmogorov-Smirnov test was applied to test the normality distribution. To explore the independent nature of some categorical variables, a chi-square test was used. The comparison of the means between two related groups was made by paired T-test or Wilcoxon 
signed ranks. Generalized estimation equation (GEE) analysis was applied to test the effect of time on longitudinal data.

\section{Results}

In this research, patients underwent cell therapy using WJ-MSC. All patients needed oxygen masks, and four of them were admitted to ICU, and one patient remained out of ICU. All patients received common treatments, including heparin and dexamethasone. Preliminary characteristics of patients such as age, sex, weight, initial baseline symptoms, duration of symptoms before hospitalization and first cell injection, ICU hospitalization period following cell injection, comorbidities, disease severity, and common drugs are listed in Table 1. All the patients were monitored for vital signs such as pulse, respiration, heart rate, blood pressure, $\mathrm{SO}_{2}$, and fever at the time of injection and $1 \mathrm{~h}$ later. In this study, no serious complication associated with WJ-MSC stem cells was observed. Only patient no. 3 had a slight post-injection headache that resolved without any drug after half an hour. The above statements indicate that WJ-MSC is safe and tolerable for the patient. There was zero mortality rate within the first 28 days.

Flow cytometry analysis was performed on patient samples before and after cell therapy with WJ-MSC, and the upward trend of CD4 and CD8 markers is shown in
Fig. 1, in which the improvement of lymphocyte population can be observed (more details of these markers are listed in the supplementary data file, i.e., Fig.S1a \& b). In this study, the percentage of lymphocytes, absolute lymphocyte count, and CD4 and CD8 T cell ratio increased, indicating the improvement in immune system function after cell therapy with WJ-MSC (Table 2). Routine hematology tests (WBC, Hb, PLT, neutrophil and lymphocyte percentage, absolute lymphocyte count, ESR, and D-dimer), myocardial enzyme tests (CPK, LDH, and Troponin I), biochemical tests (ALT, AST, Cr, BUN, total and direct bilirubin, $\mathrm{K}, \mathrm{Na}$, and ferritin), and inflammation tests (ESR, CRP, and procalcitonin) were conducted for all patients before and after cell therapy on base and days 3, 6, and 14, which are shown in Table 2 . The results indicated the improvement of test results over time. We statistically examined four of these tests that are more important for five COVID-19 patients of our study, including LDH, CRP, lymph count, and ferritin, among which ferritin showed a significant decrease (supplementary data, Fig. S2).

In this study, the trend of oxygen saturation percentage among patients over MSC injection days (admission day, days 0,3 , and 6; supplementary data, Fig. S3-a), at the time of injection, and 15, 30, 45, and $60 \mathrm{~min}$ after it is shown in Fig. 3-b (supplementary data).

In this research, we examined inflammatory cytokines, angiogenesis, and implantation in the days before and

Table 1 Demographic data

\begin{tabular}{|c|c|c|c|c|c|}
\hline Patient ID & Patient 1 & Patient 2 & Patient 3 & Patient 4 & Patient 5 \\
\hline Gender & Female & Female & Male & Male & Male \\
\hline Age & 51 & 51 & 54 & 45 & 53 \\
\hline Weight & 94 & 70 & 88 & 95 & 102 \\
\hline \multicolumn{6}{|l|}{ Initial vital signs (base) } \\
\hline RR breaths/min & 22 & 28 & 42 & 36 & 28 \\
\hline PR beats/min & 71 & 92 & 89 & 66 & 92 \\
\hline Sys BP, mmHg & 141 & 103 & 124 & 139 & 138 \\
\hline Dias BP, mmHg & 76 & 71 & 89 & 90 & 97 \\
\hline Temp > $37.3\left({ }^{\circ} \mathrm{C}\right.$, baseline $)$ & 37 & 37.3 & 36.7 & 37.4 & 36.2 \\
\hline $\mathrm{SO}_{2}$ (without oxygen mask) & 87 & 70 & 79 & 80 & 89 \\
\hline \multicolumn{6}{|l|}{ Other } \\
\hline COVID type & Sev & Sev & Sev & Sev & Sev \\
\hline Comorbidities & Fatty liver disease & HTN & Damaged lung & No & Diabetes \\
\hline Interval between symptoms onset and admission (days) & 6 & 10 & 11 & 13 & 4 \\
\hline Interval between symptoms onset and first cell injection (days) & 10 & 14 & 13 & 17 & 7 \\
\hline Duration of hospitalization in ICU after cell injection & 7 & 5 & 0 & 6 & 0 \\
\hline Conventional therapy & Hep/Dexa & Hep/Dexa & Hep/Dexa & Hep/Dexa & Hep/Dexa/Ataz \\
\hline RT-PCR at admission & + & + & + & + & + \\
\hline
\end{tabular}

Sev severe, HTN hypertension, Hep heparin, Dexa dexamethasone, Ataz atazanavir, RT-PCR reverse transcription polymerase chain reaction 


\section{CD4\&CD8}

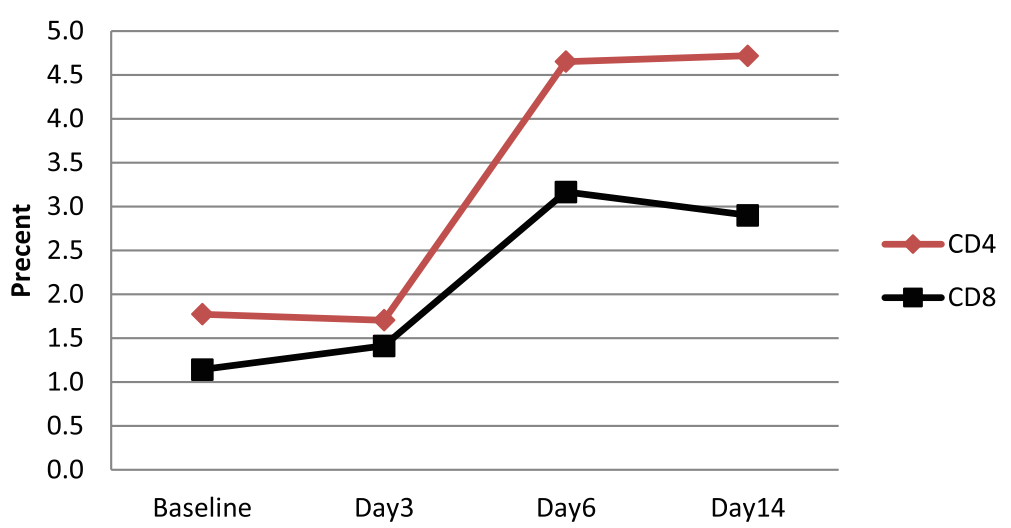

Fig. 1 Measured markers of CD4 and CD8 on patients with COVID-19 before and after treatment

after cell therapy, as shown in Fig. 2. The results show that over 14 days before and after cell therapy, SDF-1 and IL-10 levels increased, but VEGF, TGF- $\beta$, IFN- $\gamma$, IL6 , and TNF $\alpha$ decreased.

COVID-19 antibody test in the days before treatment and 14 days after it are shown in Fig. S4 (Supplementary data, Fig. S4).

\section{CT scan}

Table 3 lists CT scan results of parenchymal abnormalities, type of GGO opacities, zonal involvement, total score, and cardiomegaly. None of the patients had pleural effusion. One patient showed mild (patient no. 2) pericardial effusion before cell injection and14 days after it but was free of pericardial effusion on day 28. Mild P4 emphysema was observed on days 14 and 28. None of the patients showed pulmonary fibrosis. Patient no. 5 showed mild bronchiectasis the day before cell therapy and at day 14. All patients (except for patient no. 3) showed mild to moderate cardiomegaly. In patient no. 1 , the mosaicism pattern was completely resorbed on day 28 , patient P2 showed severe mosaicism on day 28, patient no. 3 had moderate mosaicism on day 14 and mild mosaicism on day 28 , and finally, patient no. 4 showed severe mosaicism on days 14 and 28. Patient no. 5 had no mosaicism. Chest computerized tomography (CT) images of the two COVID-19 patients are demonstrated in Fig. 3a, b.

\section{Discussion}

Most patients show a tolerant response to COVID-19 infection. When the virus enters the lungs, immune system cells are recalled to the infected area to defend the body against the virus and elicit an immune response [39]. In some cases, the increase in cytokines secreted by this response leads to cytokine storm, followed by inflammation, tissue damage, secondary infection, and ARDS, leading to death $[40,41]$. Therefore, inhibition of cytokine storms in patients with COVID-19 can be crucial in treating these patients [24].

Studies have revealed that mesenchymal stem cells are involved in improving lymphocyte populations mainly through dendritic cells and shifting immune system cells' response from Th1 to Th2 [42]. TCD8 cells are of high importance in killing virus-infected cells [43]. TCD4 cells play an essential role in the immune response by helping TCD8 and B cells to produce antibodies [44]. Various investigations have indicated that in patients with severe COVID-19, both TCD4 and TCD8 are reduced [45]. In our study, both TCD4 and TCD8 cells were recovered after cell therapy. A clinical trial was conducted in China on seven patients with COVID-19 pneumonia injected with mesenchymal stem cells. Patients who showed no improvement in symptoms compared to conventional treatment were recruited [13]. MSCs inhibit the overactivation immune system and promote endogenous repair by improving the microenvironment. In this study, it was stated that after IV injection of MSCs, these cells accumulated in the lungs and could improve the pulmonary microenvironment, prevent pulmonary fibrosis, and improve lung function [13]. According to Cao team reports, serum levels of IL2, IL-7, GCSF, IP10, MCP1, MIP1A, and TNF $\alpha$ were considerably higher in ICU patients compared to ordinary people [12]. This research showed that IV injection of MSCs improves inflammation in patients with severe COVID-19. Besides, increasing IL-10 and VEGF promotes lung repair [13]. In a study by Lanzoni et al., the safety and, to some extent, the efficacy of hUC-MSC cells in ARDS patients induced by COVID-19 was evaluated. Patients received $100 \pm 20 \times 10^{6}$ cells in two doses intravenously. They took drugs such as remdesivir, 


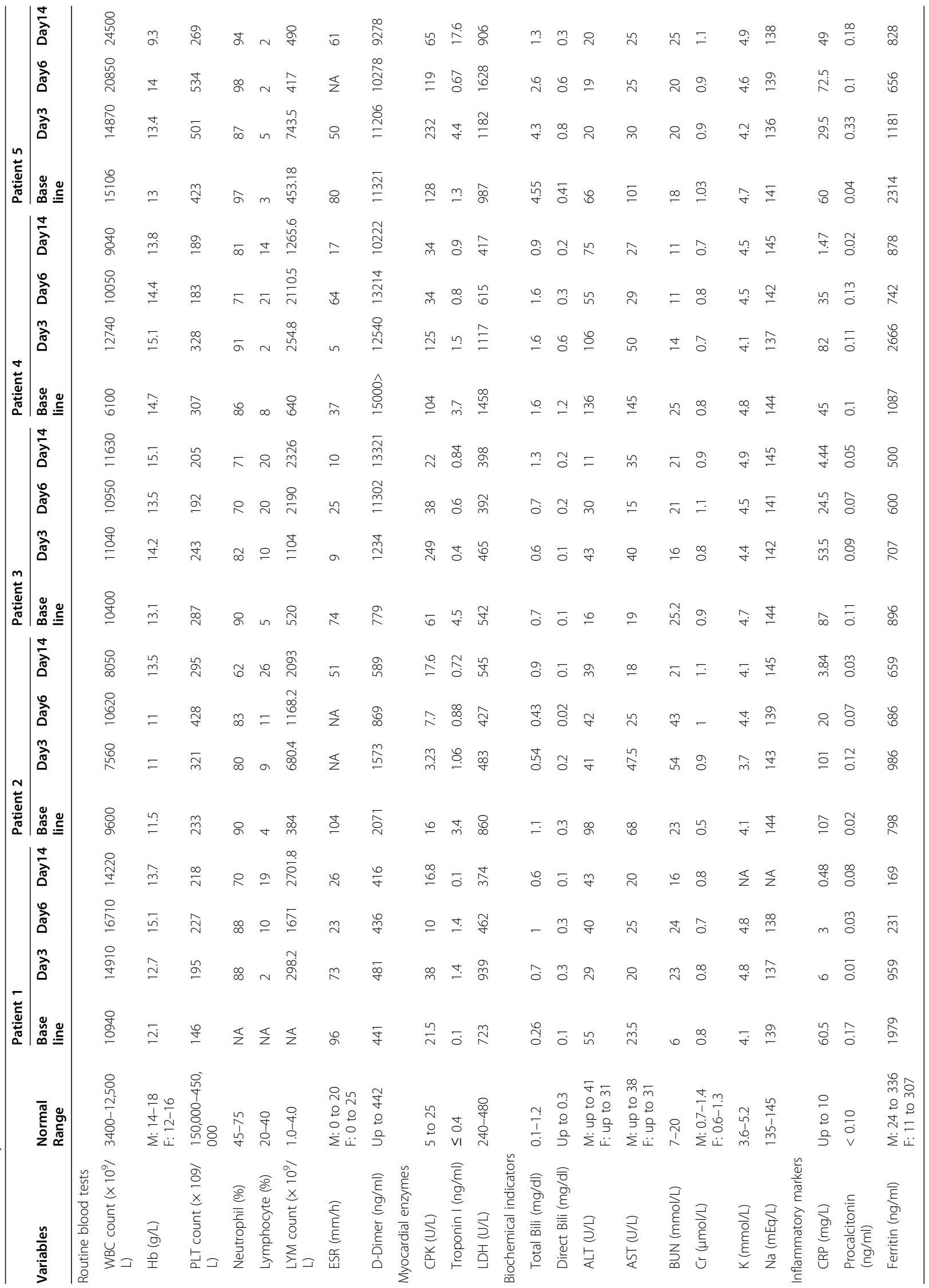


SDF-1

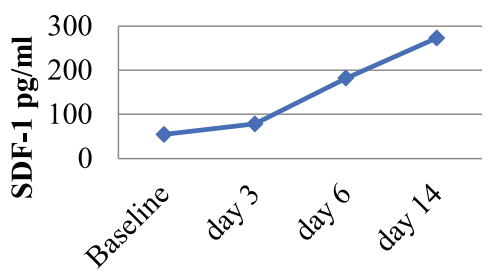

TGF- $\beta 1$

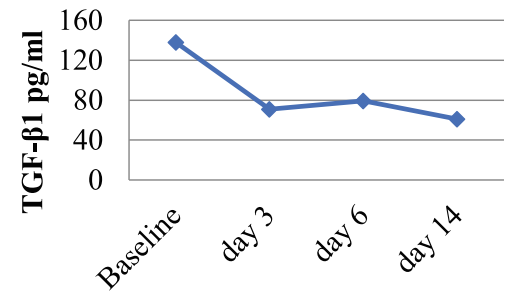

TNF- $\alpha$

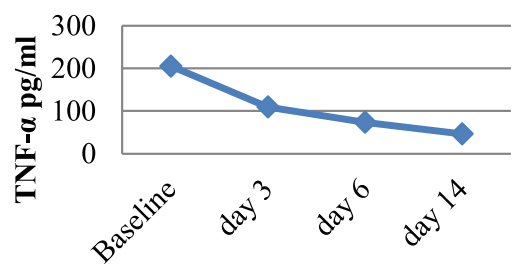

IL-10

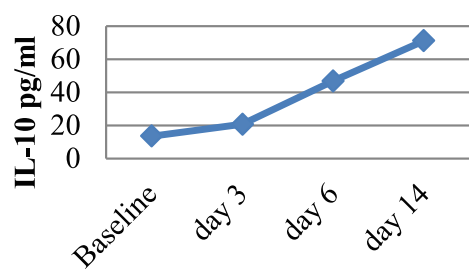

\section{IFN-8}

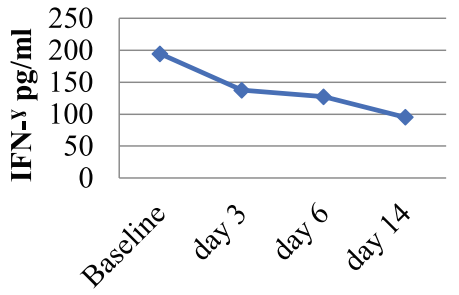

IL-6

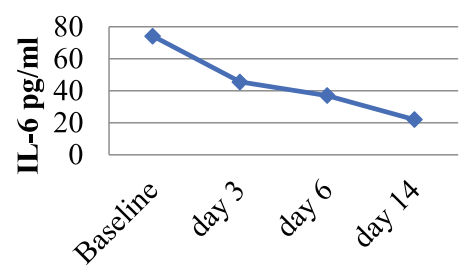

\section{VEGF}

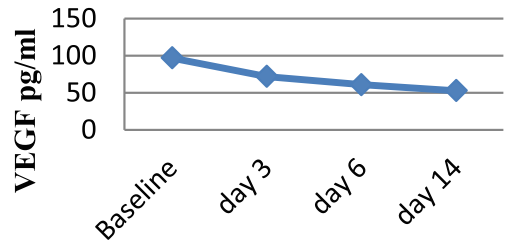

Fig. 2 Inflammatory cytokines. SDF-1 : stromal cell-derived factor 1, IL-10 : Interleukin 10, TGF- $\beta 1$ : Transforming growth factor beta 1, IFN : Interferon gamma, TNF-a : Tumor necrosis factor alpha,IL-6: Interleukin 6, VEGF : Vascular endothelial growth factor

corticosteroids, hydroxychloroquine, and tocilizumab together with the cells. In this study, they stated that hUC-MSC cells are safe in these patients and significantly reduce side effects and death and improve recovery time compared to the control group [46]. In another research by Hashemian et al., both PL-MSC and UCMSC cells were used in ARDS patients. Patients received
$200 \times 10^{6}$ cells at three doses through intravenous infusion with IVIG, ribavirin, and favipiravir. In these patients, factors such as IL-6, IL-8, TNF $\alpha$, INF- $\gamma$, IL-4, IL-10, and CRP were also evaluated. This research stated that placental and umbilical cord stem cell injections are safe and can quickly improve respiratory symptoms reducing inflammatory factors in several patients [47]. 


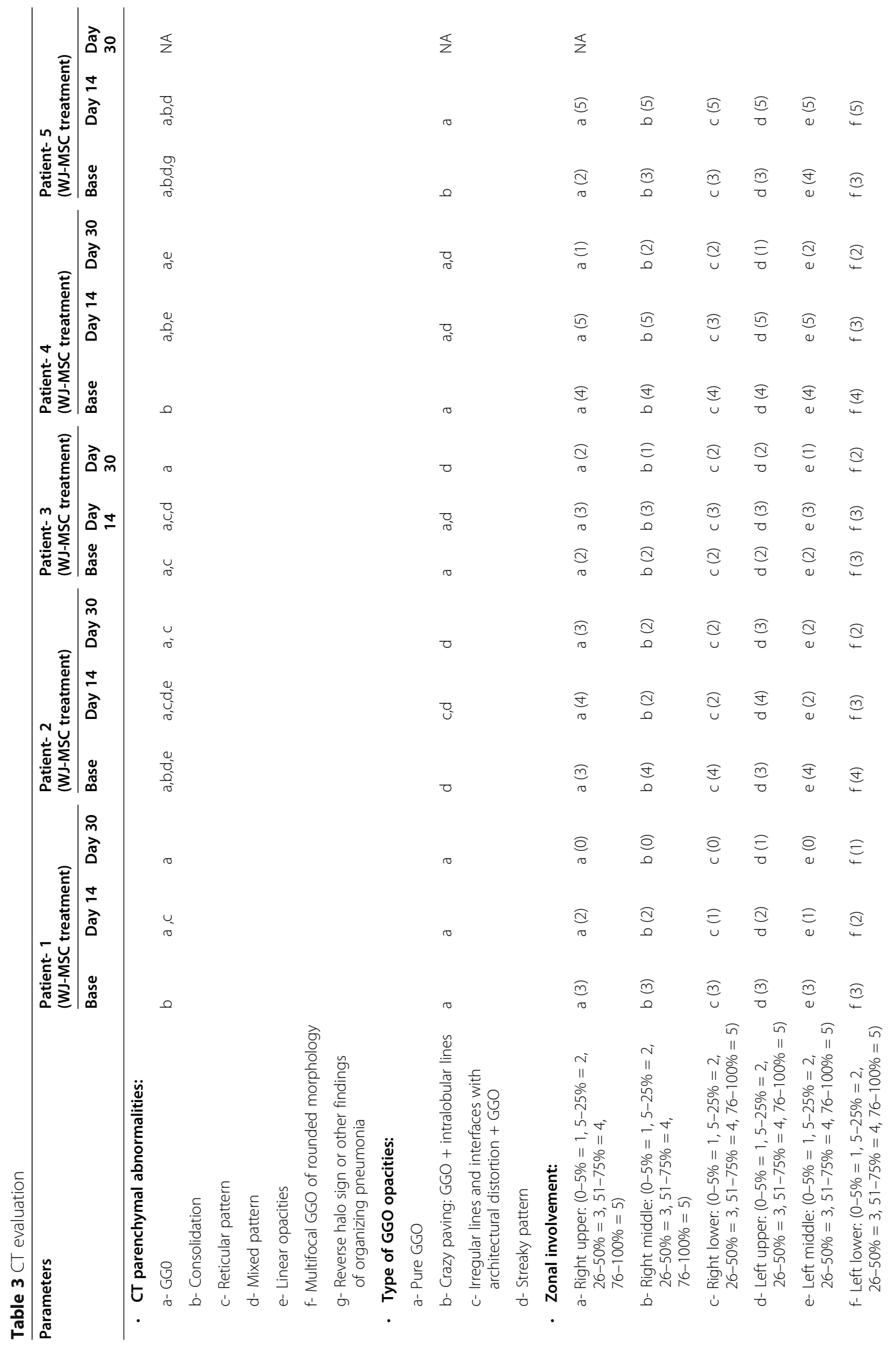




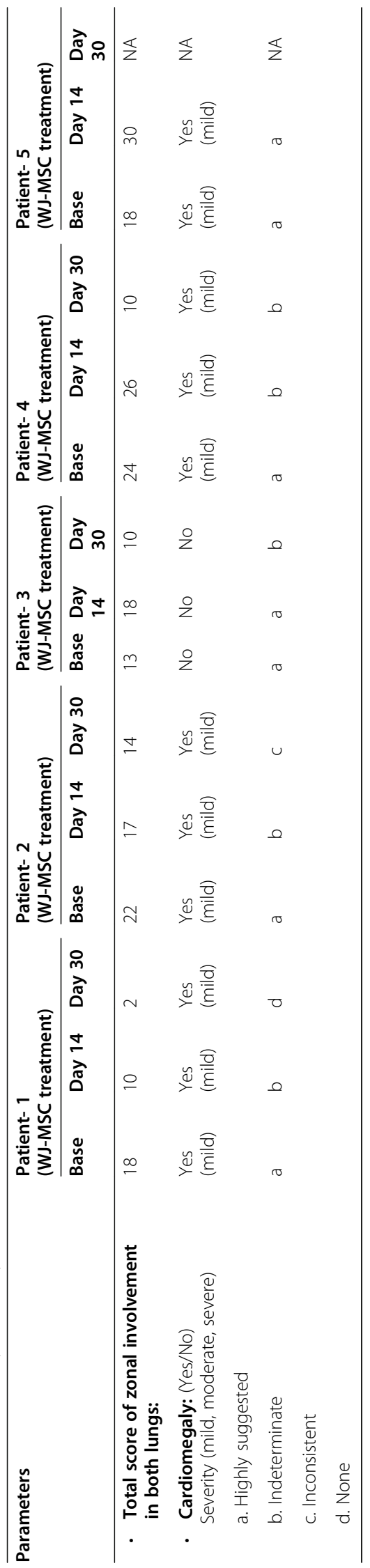



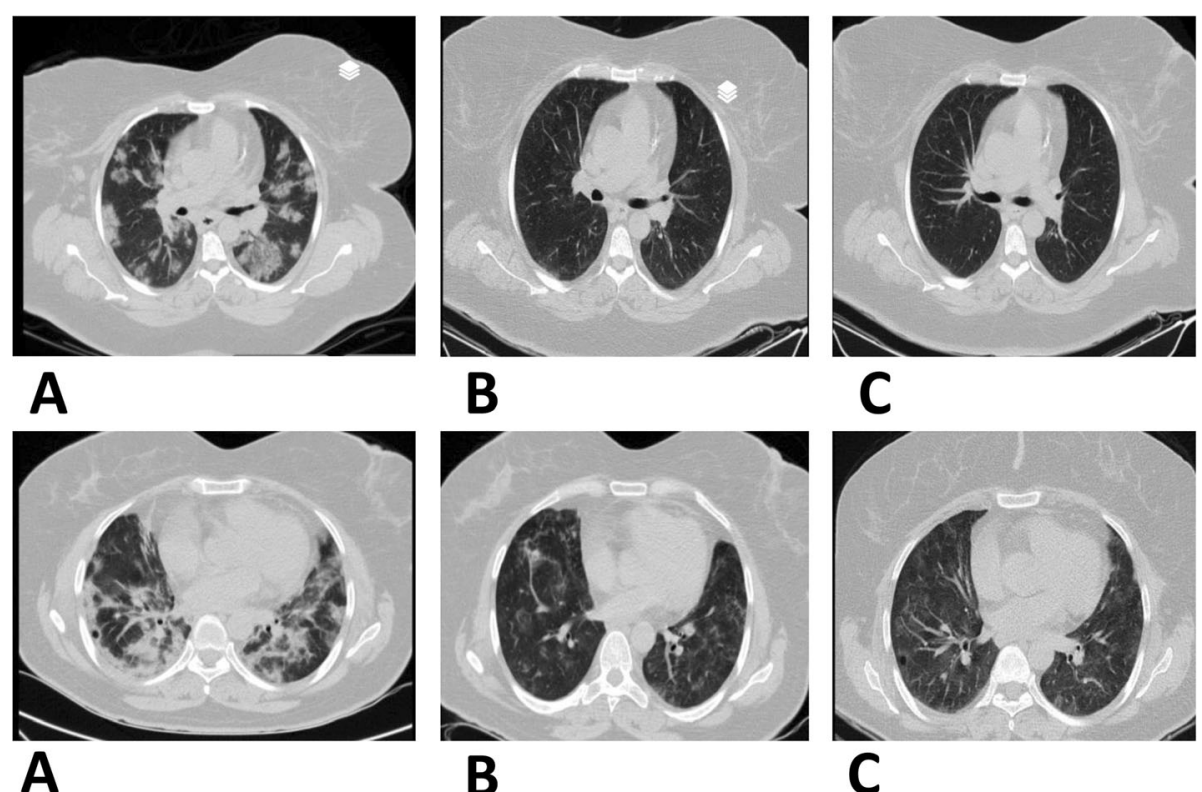

C

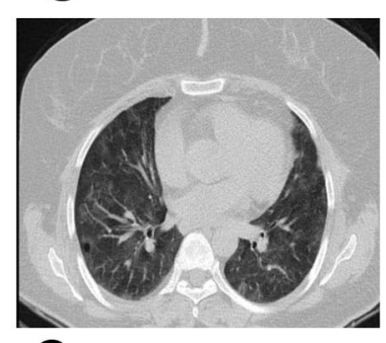

B

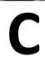

Fig. 3 Lung CT scan. a (A-C) There are multifocal patchy alveolar opacities in both lungs that in follow-up exam 14 days and 30 days later disappeared following stem cell therapy. P1: Patient 1. b (A-C) There are multifocal patchy alveolar opacities in both lungs that in follow-up exam 14 days and 30 days later disappeared following stem cell therapy. P2: Patient 2

SDF-1 factor is a cytokine that plays a crucial role in organ formation and repair after injury [48]. In a number of MSC implantation studies, it has been shown that increasing SDF-1 levels after tissue injury plays an essential role in the accumulation of mesenchymal stem cells at the site of injury [49-51]. Increased SDF-1 also increases CXCR4 expression on mesenchymal stem cells and plays a vital role in transplantation of these cells into damaged tissue [52]. Another study indicated that using SDF-1 along with WJ-MSC cells increased the migration of these cells in vitro [53]. VEGF is a significant factor in acute lung injury and ARDS, and the increase of that can be seen in acute inflammation and hypoxia $[54,55]$. In addition to angiogenesis, VEGF increases vascular leakage and permeability $[56,57]$. Studies have indicated that VEGF concentrations increase in patients with COVID19 admitted to the ICU and those outside it [3]. In our research, VEGF was gradually reduced after WJ-MSC cell therapy. In one of our patients (no. 1) in the days before cell therapy, there was a bloody sputum complaint, which may be due to increased level of VEGF and subsequently increased permeability of small pulmonary arteries. The rise in VEGF level was more prominent in this patient than in other patients, which resolved after receiving the first dose of cells within $24 \mathrm{~h}$. Mesenchymal stem cell injections reduce TGF- $\beta$, IFN- $\gamma$, and TNF $\alpha$ levels in the lung. In our study, similar to others [58, 59], inflammatory factors including IL-6,
TNF $\alpha$, and related factors associated with pulmonary fibrosis were reduced, including TGF- $\beta$ and IFN- $\gamma$. In this research, it seems that the time of cell injection in these patients is of high importance, and it can be stated that the optimal time for cell injection is the second week of the disease, namely the second phase of disease or hyper inflammation [60] beginning on days 7 to 15 .

\section{Conclusions}

This study showed that the injection of Wharton's jellyderived stem cells was safe and well-tolerated by the patient. From our perspective, the timing of stem cell injections in patients with severe COVID19 is critical. It seems that it is better to inject these cells in the inflammatory phase, and for this purpose, we should check inflammatory tests for the patient before cell injection. Considering the behavior of mesenchymal stem cells, it seems that paying attention to the precise protocols of isolation, culture, proliferation, an appropriate number, manner, and time of proper injection into humans can be the beginning of a new treatment strategy in COVID19. Further studies should be conducted to prove the effective outcomes using control and treatment groups to indicate these significant differences. It is also necessary to increase the sample size and use randomization methods in further studies to indicate these cells' positive function and improve the disease. 


\section{Supplementary Information}

The online version contains supplementary material available at https://doi. org/10.1186/s13287-021-02483-7.

Additional file 1: Figure S1. flowcytometry. a. Patient 2, Lymphocyte regeneration, A. control, B. base (before WJ-MSC injection), C.day3, D.day6 and E. day 14 after WJ-MSC injection. b. Patient 4, Lymphocyte regeneration, A. control, B. base (before WJ-MSC injection), C.day3, D.day6 and E. day 14 after WJ-MSC injection. Figure S2. laboratory data. GEE analysis was also applied to show the effect of time on change of some main variables such as CRP, Lymph count, Ferritin and LDH. The results showed a significant change during time just for ferritin with $p$-value, 0.008. Figure S3. $O 2$ Saturation. Generalized Estimating Equation (GEE) Analysis. GEE modeling was used to show the effect of day $(0,3$ and 6$)$ and time of injection (start, $\min 15, \min 30, \min 45$ and $\min 60$ ) on O2sat change. Baseline values were entered to the GEE model as a covariate variable. The overall mean O2sat during three days had a same trend but in return, injection time has a significant effect on O2sat as mean O2sat at start is different to other injection time ( $p$-value $=0.001)$. Mean O2sat at injection time is: 91.3, 92.3, 92.3, 92.5 and 93.1. a. Mean of O2sat during time. b. Change of O2sat by patients. Figure S4. SARSCOV2 Abs. Paired Comparison AnaIysis. Mean SARSCOV2.IgM and SARSCOV2.IgG at baseline and end of study, were compared using Wilcoxon Signed-Ranks. The line charts related to both antibodies are shown in Fig.S4.

\section{Acknowledgements}

We sincerely appreciate Barkat Pharmaceutical Group Pharmed for their help with providing facilities for this study. The authors thank the members of Shariati Hospital, Dr. Saeed Reza Mehrpour (Head of Hospital), Dr. Mohammadreza Jafary (Deputy of Treatment), Dr. Masoud Rafati (Hospital Manager), Parvin Rezaei (Infection Control Nurse), and Vahideh Zaeri (Head Nurse of COVID19-ICU) for their contributions to the study.

\section{Authors' contributions}

MS proposed the initial idea, study design, and writing of the manuscript. MS, AV, RA, AS, ZK, MSH, VS, BKH, SHA, CH, LA, NA, IS, and JV were responsible for the manuscript's reference selection and writing. MS, NA, ZK, and RA took care of the patients and performed the follow-up checks. MS, $\mathrm{NA}, \mathrm{AV}$, and BKH collected and analyzed the data. MS, IS, JV, and NA contributed to the critical paper of the manuscript. MS and LA analyzed the CT. All authors read and approved the final manuscript.

\section{Funding}

The Tehran University of Medical Sciences supported this work. Tehran University of Medical Sciences provided funding for this study (ethics code IR.TUMS.VCR.REC.1399.203)

\section{Availability of data and materials}

All of the data generated and analyzed during this study are included in our manuscript.

\section{Declarations}

\section{Ethics approval and consent to participate}

Written informed consent was obtained from each patient or the patient's legally authorized surrogate before the conduct of study-specific procedures.

\section{Consent for publication}

Not relevant

\section{Competing interests}

The authors declare that they have no competing interests.

\section{Author details}

${ }^{1}$ Department of Applied Cell Sciences, School of Advanced Technologies in Medicine, Tehran University of Medical Sciences, Tehran, Iran. ${ }^{2}$ Department of Internal Medicine, Alborz University of Medical Sciences, Karaj, Iran. ${ }^{3}$ Department of Pulmonary and Critical Care, Shariati Hospital, Tehran University of Medical Sciences, Tehran, Iran. ${ }^{4}$ Advanced Thoracic Research Center, Tehran University of Medical Sciences, Tehran, Iran. ${ }^{5}$ Associate
Professor of Gastroenterology and Hepatology, Liver and Pancreatobiliary Diseases Research Center, Digestive Disease Research Institute, Tehran University of Medical Sciences, Tehran, Iran. ${ }^{6}$ Advanced Thoracic Research Centre, Tehran University of Medical Science, Tehran, Iran. ${ }^{7}$ Department of Clinical Nutrition, Faculty of Nutrition \& Food Technology, Shahid Beheshti University of Medical Sciences, Tehran, Iran. ${ }^{8}$ Department of Clinical Pathology, Faculty of Veterinary Medicine, University of Tehran, Tehran, Iran. ${ }^{9}$ Associate Professor, Department of Radiology, Shariati Hospital, Tehran University of Medical Sciences, Tehran, Iran. ${ }^{10}$ Iran Helal Institute of Applied-Science and Technology, Research Center for Health Management in Mass Gathering, Red Crescent Society of the Islamic Republic of Iran, Tehran, Iran. ${ }^{11}$ Pasteur Institute of Iran, National Cell Bank of Iran, Tehran, Iran. ${ }^{12}$ Hematology, Oncology, and Stem Cell Transplantation Research Center, Tehran University of Medical Sciences, Tehran, Iran. ${ }^{13}$ Department of Infectious Diseases, Shariati Hospital, Tehran University of Medical Sciences, Tehran, Iran.

Received: 17 February 2021 Accepted: 26 June 2021

Published online: 16 July 2021

\section{References}

1. Munster VJ, Koopmans M, van Doremalen N, van Riel D, de Wit E. A novel coronavirus emerging in China - key questions for impact assessment. New England Journal of Medicine. 2020;382(8):692-4. https://doi.org/10.1 056/NEJMp2000929.

2. Sajadi MM, Habibzadeh P, Vintzileos A, Shokouhi S, Miralles-Wilhelm F, Amoroso A. Temperature and latitude analysis to predict potential spread and seasonality for COVID-19. Available at SSRN 3550308. 2020.

3. Huang C, Wang Y, Li X, Ren L, Zhao J, Hu Y, et al. Clinical features of patients infected with 2019 novel coronavirus in Wuhan, China. Lancet. 2020;395(10223):497-506. https://doi.org/10.1016/S0140-6736(20)30183-5.

4. Shi H, Han X, Jiang N, Cao Y, Alwalid O, Gu J, et al. Radiological findings from 81 patients with COVID-19 pneumonia in Wuhan, China: a descriptive study. The Lancet Infectious Diseases. 2020;20(4):425-34. https://doi.org/10.1 016/S1473-3099(20)30086-4

5. World Health Organization. Clinical management of COVID-19: interim guidance, 27 May 2020. World Health Organization. 2020. https://apps.who. int/iris/handle/10665/332196. License: CC BY-NC-SA 3.0 IGO.

6. Xu X, Chen P, Wang J, Feng J, Zhou H, Li X, et al. Evolution of the novel coronavirus from the ongoing Wuhan outbreak and modeling of its spike protein for risk of human transmission. Science China Life Sciences. 2020; 63(3):457-60. https://doi.org/10.1007/s11427-020-1637-5.

7. Lu R, Zhao X, Li J, Niu P, Yang B, Wu H, et al. Genomic characterisation and epidemiology of 2019 novel coronavirus: implications for virus origins and receptor binding. Lancet (London, England). 2020;395(10224):565-74.

8. Zhou $P$, Yang $X L$, Wang $X G$, Hu B, Zhang L, Zhang W, et al. A pneumonia outbreak associated with a new coronavirus of probable bat origin. Nature. 2020:579(7798):270-3. https://doi.org/10.1038/s41586-020-2012-7.

9. Hamming I, Timens W, Bulthuis ML, Lely AT, Navis G, van Goor H. Tissue distribution of ACE2 protein, the functional receptor for SARS coronavirus. A first step in understanding SARS pathogenesis. The Journal of pathology. 2004:203(2):631-7. https://doi.org/10.1002/path.1570.

10. Metcalfe SM. Mesenchymal stem cells and management of COVID-19 pneumonia. Medicine in drug discovery. 2020;100019.

11. Ye Q, Wang B, Mao J. The pathogenesis and treatment of the 'cytokine storm' in COVID-19. Journal of infection. 2020;80(6):607-13. https://doi.org/1 0.1016/j.jinf.2020.03.037.

12. Huang $C$, Wang $Y$, Li X, Ren L, Zhao J, Hu Y, et al. Clinical features of patients infected with 2019 novel coronavirus in Wuhan, China. Lancet (London, England). 2020;395(10223):497-506.

13. Huang $P$, Liu $T$, Huang $L$, Liu H, Lei $M, X u$ W, et al. Use of chest $C T$ in combination with negative RT-PCR assay for the 2019 novel coronavirus but high clinical suspicion. Radiology. 2020;295(1):22-3. https://doi.org/10.1148/ radiol.2020200330

14. Kavianpour M, Saleh M, Verdi J. The role of mesenchymal stromal cells in immune modulation of COVID-19: focus on cytokine storm. Stem Cell Research \& Therapy. 2020;11(1):1-19, 404, DOI: https://doi.org/10.1186/s132 87-020-01849-7.

15. Harrell CR, Sadikot R, Pascual J, Fellabaum C, Jankovic MG, Jovicic N, et al. Mesenchymal stem cell-based therapy of inflammatory lung diseases: 
current understanding and future perspectives. Stem cells international. 2019:2019:1-14. https://doi.org/10.1155/2019/4236973.

16. Tsuchiya A, Kojima Y, Ikarashi S, Seino S, Watanabe Y, Kawata Y, et al. Clinical trials using mesenchymal stem cells in liver diseases and inflammatory bowel diseases. Inflammation and Regeneration. 2017;37(1):16. https://doi. org/10.1186/s41232-017-0045-6.

17. Ribeiro-Paes JT, Bilaqui A, Greco OT, Ruiz MA, Marcelino MY, Stessuk T, et al. Unicentric study of cell therapy in chronic obstructive pulmonary disease/ pulmonary emphysema. International Journal of Chronic Obstructive Pulmonary Disease. 2011;6:63.

18. Tzouvelekis A, Paspaliaris V, Koliakos G, Ntolios P, Bouros E, Oikonomou A, et al. A prospective, non-randomized, no placebo-controlled, phase lb clinical trial to study the safety of the adipose derived stromal cells-stromal vascular fraction in idiopathic pulmonary fibrosis. Journal of translational medicine. 2013;11(1):171. https://doi.org/10.1186/1479-5876-11-171.

19. Chambers DC, Enever D, llic N, Sparks L, Whitelaw K, Ayres J, et al. A phase $1 \mathrm{~b}$ study of placenta-derived mesenchymal stromal cells in patients with idiopathic pulmonary fibrosis. Respirology. 2014;19(7):1013-8. https://doi. org/10.1111/resp.12343.

20. Glassberg MK, Minkiewicz J, Toonkel RL, Simonet ES, Rubio GA, DiFede D, et al. Allogeneic human mesenchymal stem cells in patients with idiopathic pulmonary fibrosis via intravenous delivery (AETHER): a phase I safety clinical trial. Chest. 2017;151(5):971-81. https://doi.org/10.1016/j.chest.2016.10.061.

21. Ntolios P, Manoloudi E, Tzouvelekis A, Bouros E, Steiropoulos P, Anevlavis S, et al. Longitudinal outcomes of patients enrolled in a phase Ib clinical trial of the adipose-derived stromal cells-stromal vascular fraction in idiopathic pulmonary fibrosis. The Clinical Respiratory Journal. 2018;12(6):2084-9. https://doi.org/10.1111/crj.12777.

22. Böttcher H, Eisbrenner K, Fritz S, Kindermann G, Kraxner F, McCallum I, et al. An assessment of monitoring requirements and costs of 'Reduced Emissions from Deforestation and Degradation'. Carbon balance and management. 2009;4(1):7. https://doi.org/10.1186/1750-0680-4-7.

23. Hashmi S, Ahmed M, Murad MH, Litzow MR, Adams RH, Ball LM, et al. Survival after mesenchymal stromal cell therapy in steroid-refractory acute graft-versushost disease: systematic review and meta-analysis. The Lancet Haematology. 2016;3(1):e45-52. https://doi.org/10.1016/S2352-3026(15)00224-0.

24. Kavianpour M, Saleh M, Verdi J. The role of mesenchymal stromal cells in immune modulation of COVID-19: focus on cytokine storm. Stem Cell Research \& Therapy. 2020;11(1):404. https://doi.org/10.1186/s13287020-01849-7.

25. Saburi E, Abazari MF, Hassannia H, Mansour RN, Eshaghi-Gorji R, Gheibi M, et al. The use of mesenchymal stem cells in the process of treatment and tissue regeneration after recovery in patients with Covid-19. Gene. 2021; 777(145471.10):1016.

26. Galipeau J, Sensébé L. Mesenchymal stromal cells: clinical challenges and therapeutic opportunities. Cell Stem Cell. 2018;22(6):824-33. https://doi. org/10.1016/j.stem.2018.05.004.

27. HassR K, Böhm S, et al. Different populations and sources of human mesenchymal stem cells (MSC): a comparison of adult and neonatal tissuederived MSC. Cell Commun Signal. 2011;9:12.

28. Fong C-Y, Chak L-L, Biswas A, Tan J-H, Gauthaman K, Chan W-K, et al. Human Wharton's jelly stem cells have unique transcriptome profiles compared to human embryonic stem cells and other mesenchymal stem cells. Stem Cell Reviews and Reports. 2011;7(1):1-16. https://doi.org/10.1007/ s12015-010-9166-x.

29. El Omar R, Beroud J, Stoltz J-F, Menu P, Velot E, Decot V. Umbilical cord mesenchymal stem cells: the new gold standard for mesenchymal stem cell-based therapies? Tissue Engineering Part B: Reviews. 2014;20(5):523-44. https://doi.org/10.1089/ten.teb.2013.0664.

30. Aggarwal S, Pittenger MF. Human mesenchymal stem cells modulate allogeneic immune cell responses. Blood. 2005;105(4):1815-22. https://doi. org/10.1182/blood-2004-04-1559.

31. Gunn WG, Conley A, Deininger L, Olson SD, Prockop DJ, Gregory CA. A crosstalk between myeloma cells and marrow stromal cells stimulates production of DKK1 and interleukin-6: a potential role in the development of lytic bone disease and tumor progression in multiple myeloma. Stem cells. 2006;24(4):986-91. https://doi.org/10.1634/stemcells.2005-0220.

32. Zhang $Y$, Ding J, Ren $S$, Wang W, Yang Y, Li S, et al. Intravenous infusion of human umbilical cord Wharton's jelly-derived mesenchymal stem cells as a potential treatment for patients with COVID-19 pneumonia. Stem cell research \& therapy. 2020;11(1):1-6.
33. Waterman RS, Tomchuck SL, Henkle SL, Betancourt AM. A new mesenchymal stem cell (MSC) paradigm: polarization into a proinflammatory MSC1 or an immunosuppressive MSC2 phenotype. PLOS ONE. 2010:5(4):e10088. https://doi.org/10.1371/journal.pone.0010088.

34. Li W, Ren G, Huang Y, Su J, Han Y, Li J, et al. Mesenchymal stem cells: a double-edged sword in regulating immune responses. Cell Death and Differentiation. 2012;19(9):1505-13. https://doi.org/10.1038/cdd.2012.26.

35. Maron-Gutierrez T, Laffey JG, Pelosi P, Rocco PR. Cell-based therapies for the acute respiratory distress syndrome. Current opinion in critical care. 2014; 20(1):122-31. https://doi.org/10.1097/MCC.0000000000000061.

36. Abreu SC, Weiss DJ, Rocco PR. Extracellular vesicles derived from mesenchymal stromal cells: a therapeutic option in respiratory diseases? Stem cell research \& therapy. 2016;7(1):53. https://doi.org/10.1186/s13287-016-0317-0.

37. Phinney DG, Pittenger MF. Concise review: MSC-derived exosomes for cellfree therapy. Stem cells (Dayton, Ohio). 2017;35(4):851-8.

38. WHO-China. Report of the WHO-China Joint Mission on Coronavirus Disease 2019 (COVID-19).

39. Astuti I. Ysrafil. Severe Acute Respiratory Syndrome Coronavirus 2 (SARSCoV-2): an overview of viral structure and host response. Diabetes Metab Syndr. 2020;14(4):407-12. https://doi.org/10.1016/j.dsx.2020.04.020.

40. Mehta P, McAuley DF, Brown M, Sanchez E, Tattersall RS, Manson JJ, et al. COVID-19: consider cytokine storm syndromes and immunosuppression. Lancet (London, England). 2020;1033(10229):95.

41. Guo T, Fan Y, Chen M, Wu X, Zhang L, He T, et al. Cardiovascular implications of fatal outcomes of patients with coronavirus disease 2019 (COVID-19). JAMA cardiology. 2020;5(7):811-8. https://doi.org/10.1001/jama cardio.2020.1017.

42. Leng Z, Zhu R, Hou W, Feng Y, Yang Y, Han Q, et al. Transplantation of ACE2-mesenchymal stem cells improves the outcome of patients with COVID-19 pneumonia. Aging and disease. 2020;11(2):216-28. https://doi. org/10.14336/AD.2020.0228.

43. Zheng $\mathrm{H}-\mathrm{Y}$, Zhang $\mathrm{M}$, Yang $\mathrm{C}-\mathrm{X}$, Zhang $\mathrm{N}$, Wang $\mathrm{X}-\mathrm{C}$, Yang $\mathrm{X}-\mathrm{P}$, et al. Elevated exhaustion levels and reduced functional diversity of $\mathrm{T}$ cells in peripheral blood may predict severe progression in COVID-19 patients. Cellular \& molecular immunology. 2020;17(5):541-3. https://doi.org/10.1038/ s41423-020-0401-3.

44. Crotty S. T follicular helper cell biology: a decade of discovery and diseases. Immunity. 2019;50(5):1132-48. https://doi.org/10.1016/j.immuni.2019.04.011.

45. Kalpakci Y, Hacibekiroglu T, Trak G, Karacaer C, Demirci T, Kocayigit H, et al. Comparative evaluation of memory T cells in COVID-19 patients and the predictive role of CD4 + CD8+ double positive T lymphocytes as a new marker. Revista da Associação Médica Brasileira. 2020;66(12):1666-72. https:// doi.org/10.1590/1806-9282.66.12.1666

46. Lanzoni G, Linetsky E, Correa D, Messinger Cayetano S, Alvarez RA, Kouroupis D, et al. Umbilical cord mesenchymal stem cells for COVID-19 acute respiratory distress syndrome: A double-blind, phase 1/2a, randomized controlled trial. Stem cells translational medicine.

47. Hashemian S-MR, Aliannejad R, Zarrabi M, Soleimani M, Vosough M, Hosseini S-E, et al. Mesenchymal stem cells derived from perinatal tissues for treatment of critically ill COVID-19-induced ARDS patients: a case series. Stem cell research \& therapy. 2021;12(1):1-12.

48. Ratajczak M, Zuba-Surma E, Kucia M, Reca R, Wojakowski W, Ratajczak J. The pleiotropic effects of the SDF-1-CXCR4 axis in organogenesis, regeneration and tumorigenesis. Leukemia. 2006;20(11):1915-24. https://doi.org/10.1038/ sj.leu.2404357.

49. Xiao Ling K, Peng L, Jian Feng Z, Wei C, Wei Yan Y, Nan S, et al. Stromal derived factor-1/CXCR4 axis involved in bone marrow mesenchymal stem cells recruitment to injured liver. Stem cells international. 2016;2016:1-10. https://doi.org/10.1155/2016/8906945.

50. Pillarisetti K, Gupta SK. Cloning and relative expression analysis of rat stromal cell derived factor-1 (SDF-1): SDF-1 a mRNA is selectively induced in rat model of myocardial infarction. Inflammation. 2001;25(5):293-300. https://doi.org/10.1023/A:1012808525370.

51. Askari AT, Unzek S, Popovic ZB, Goldman CK, Forudi F, Kiedrowski M, et al. Effect of stromal-cell-derived factor 1 on stem-cell homing and tissue regeneration in ischaemic cardiomyopathy. The Lancet. 2003;362(9385):697703. https://doi.org/10.1016/S0140-6736(03)14232-8.

52. Deng Q-J, Xu X-F, Ren J. Effects of SDF-1/CXCR4 on the repair of traumatic brain injury in rats by mediating bone marrow derived mesenchymal stem cells. Cellular and molecular neurobiology. 2018:38(2):467-77. https://doi. org/10.1007/s10571-017-0490-4. 
53. Kowalski K, Kołodziejczyk A, Sikorska M, Płaczkiewicz J, Cichosz P, Kowalewska $M$, et al. Stem cells migration during skeletal muscle regeneration-the role of Sdf-1/Cxcr4 and Sdf-1/Cxcr7 axis. Cell adhesion \& migration. 2017;11(4):384-98. https://doi.org/10.1080/19336918.2016.1227911

54. Medford A, Millar A. Vascular endothelial growth factor (VEGF) in acute lung injury (ALI) and acute respiratory distress syndrome (ARDS): paradox or paradigm? Thorax. 2006;61(7):621-6. https://doi.org/10.1136/thx.2005.040204.

55. Tuder RM, Flook BE, Voelkel NF. Increased gene expression for VEGF and the VEGF receptors KDR/FIk and Flt in lungs exposed to acute or to chronic hypoxia. Modulation of gene expression by nitric oxide. The Journal of clinical investigation. 1995;95(4):1798-807. https://doi.org/10.1172/JCl117858.

56. Cosky EEP, Ding Y. The role of vascular endothelial growth factor in angiogenesis and brain circulation after stroke. Brain Circ. 2018;4(2):73-5. https://doi.org/10.4103/bc.bc_8_18.

57. Kong Y, Han J, Wu X, Zeng H, Liu J, Zhang H. VEGF-D: a novel biomarker for detection of COVID-19 progression. Critical Care. 2020;24(1):1-4.

58. Moodley Y, Atienza D, Manuelpillai U, Samuel CS, Tchongue J, llancheran S, et al. Human umbilical cord mesenchymal stem cells reduce fibrosis of bleomycin-induced lung injury. The American journal of pathology. 2009; 175(1):303-13. https://doi.org/10.2353/ajpath.2009.080629.

59. Zhou C, Yang B, Tian Y, Jiao H, Zheng W, Wang J, et al. Immunomodulatory effect of human umbilical cord Wharton's jelly-derived mesenchymal stem cells on lymphocytes. Cellular immunology. 2011;272(1):33-8. https://doi. org/10.1016/j.cellimm.2011.09.010

60. Taboada M, Caruezo V, Naveira A, Atanassoff PG. Corticosteroids and the hyper-inflammatory phase of the COVID-19 disease. J Clin Anesth. 2020;66: 109926.

\section{Publisher's Note}

Springer Nature remains neutral with regard to jurisdictional claims in published maps and institutional affiliations.

Ready to submit your research? Choose BMC and benefit from:

- fast, convenient online submission

- thorough peer review by experienced researchers in your field

- rapid publication on acceptance

- support for research data, including large and complex data types

- gold Open Access which fosters wider collaboration and increased citations

- maximum visibility for your research: over $100 \mathrm{M}$ website views per year

At BMC, research is always in progress.

Learn more biomedcentral.com/submissions 